\title{
FIBRO-ODONTOMA AMELOBLÁSTICO: RELATO DE CASO
}

Bruno Viezzer FERNANDES, Tito Lúcio FERNANDES

O fibro-odontoma ameloblástico (FOA) é um tumor odontogênico raro, misto e de desenvolvimento lento e não agressivo. Normalmente está associado a um dente não erupcionado, prevalecendo nas duas primeiras décadas de vida, sem predileção por gênero ou região anatômica. Seu crescimento progressivo e indolor pode causar grandes lesões e aumento de volume. Seu aspecto radiográfico é de uma lesão uni ou multilocular radiolúcida bem definida, contendo níveis variados de material radiopaco de forma e tamanho irregulares. Microscopicamente o FOA é composto por cordões e ilhas de epitélio odontogênico e tecido mesenquimal rico em células semelhante à papila dentária, além de focos mineralizados de dentina e esmalte. Este trabalho relata um caso de FOA em paciente do sexo feminino de quatorze anos de idade com achado em radiografia panorâmica de lesão osteolítica no ângulo mandibular esquerdo. A paciente foi submetida à biópsia excisional com curetagem da lesão e exodontia do dente $38 \mathrm{sob}$ anestesia geral. No controle de um ano pós-operatório a paciente apresentou-se assintomática e sem sinais radiográficos de recidiva do tumor. O FOA pode ser tratado adequadamente através de curetagem cirúrgica sem a necessidade de remoção dos dentes adjacentes e o prognóstico é excelente, pois sua recidiva é incomum.

Palavras-chave: Fibroma; Odontoma; Dente Impactado 